\title{
Correlation of magnetic resonance imaging with neuropsychological testing in multiple sclerosis
}

\author{
S.M. Rao, PhD; G.J. Leo, DO; V.M. Haughton, MD; P. St. Aubin-Faubert, MS; and L. Bernardin, BS
}

\begin{abstract}
Article abstract_-Previous research has suggested that cerebral lesions observed on magnetic resonance imaging (MRI) of MS patients are clinically "silent." We examined the validity of this assertion by correlating neuropsychological test performance with MRI findings in 53 MS patients. We used a semiautomated quantitation system to measure three MRI variables: total lesion area (TLA), ventricular-brain ratio (VBR), and size of the corpus callosum (SCC). Stepwise multiple regression analyses indicated that TLA was a robust predictor of cognitive dysfunction, particularly for measures of recent memory, abstract/ conceptual reasoning, language, and visuospatial problem solving. SCC predicted test performance on measures of mental processing speed and rapid problem solving, while VBR did not independently predict cognitive test findings. These findings suggest that cerebral lesions in MS produce cognitive dysfunction and that MRI may be a useful predictor of cognitive dysfunction.
\end{abstract}

NEUROLOGY 1989;39:161-166

Magnetic resonance imaging (MRI) is extremely sensitive for the detection of focal areas of demyelination in patients with MS., The clinical significance of these lesions remains unclear. Their correlation with neurologic symptoms and degree of disability has been uniformly disappointing, ${ }^{3-6}$ prompting the view that MS lesions occur in brain regions that are clinically "silent." Others ${ }^{7,8}$ have recommended the use of neuropsychological testing to evaluate the possible relationship between cerebral demyelination and cognitive dysfunction.

Two studies ${ }^{9,10}$ attempted to relate cognitive dysfunction to lesions identified by MRI. Franklin et $\mathrm{al}^{9}$ examined 60 patients with chronic progressive MS and found a significant correlation $(r=0.35)$ between an overall brain lesion score and a summary score derived from a brief cognitive screening battery. Huber et al ${ }^{10}$ administered a brief battery of neuropsychological tests to $30 \mathrm{MS}$ patients, nine of whom were classified as "demented," 11 moderately cognitively impaired, and 12 minimally impaired. These investigators observed no significant group differences on three MRI indexes: total lesion score, cerebral atrophy, and severity of periventricular involvement. On the fourth index, atrophy of the corpus callosum, the "demented" patients had significantly higher ratings than the moderate and minimal cognitive impairment groups.

These two studies found significant correlations be- tween MRI variables and cognitive testing, yet the strength of the correlations was modest. Three methodologic factors may have contributed to their limited success in obtaining meaningful correlations. First, both studies relied on rating scales to measure the size of lesions from MRIs. Rating scales by definition are subjective and prone to human error. In addition, rating scales provide a more restricted range of data values than quantitative systems that measure lesions in area units; this restricted range may seriously limit the size of obtained correlations. Second, both studies used brief cognitive screening examinations. MS does not produce a uniform decline of all cognitive skills ${ }^{7,11}$; although these brief batteries covered a number of cognitive functions, they may have missed salient cognitive deficits. A more comprehensive neuropsychological examination may be more successful in measuring those cognitive functions that are influenced by MS-related cerebral pathology. Finally, cognitive test performance is affected by education and age. ${ }^{12}$ Thus, relatively uneducated or older patients may be classified as impaired on testing when they are functioning close to their premorbid level. Conversely, highly educated or younger patients may have experienced declines in cognitive performance that were undetected because their performance remained in the "average" range. Neither study attempted to control for these potential artifacts either experimentally or statistically.

From the Departments of Neurology (Drs. Rao and Leo, Ms. St. Aubin-Faubert, and Ms. Bernardin) and Radiology (Dr. Haughton), Medical College of Wisconsin, Milwaukee, WI.

Supported in part by a Research Career Development Award (K04 NS01055) and a research grant (R01 NS22128) from NINCDS to Dr. Rao.

Presented in part at the fortieth annual meeting of the American Academy of Neurology, Cincinnati, OH, April 1988.

Received May 2, 1988. Accepted for publication in final form August 8, 1988.

Address correspondence and reprint requests to Dr. Rao, Section of Neuropsychology, Medical College of Wisconsin, 1000 North 92nd Street, Milwaukee, WI 53226. 


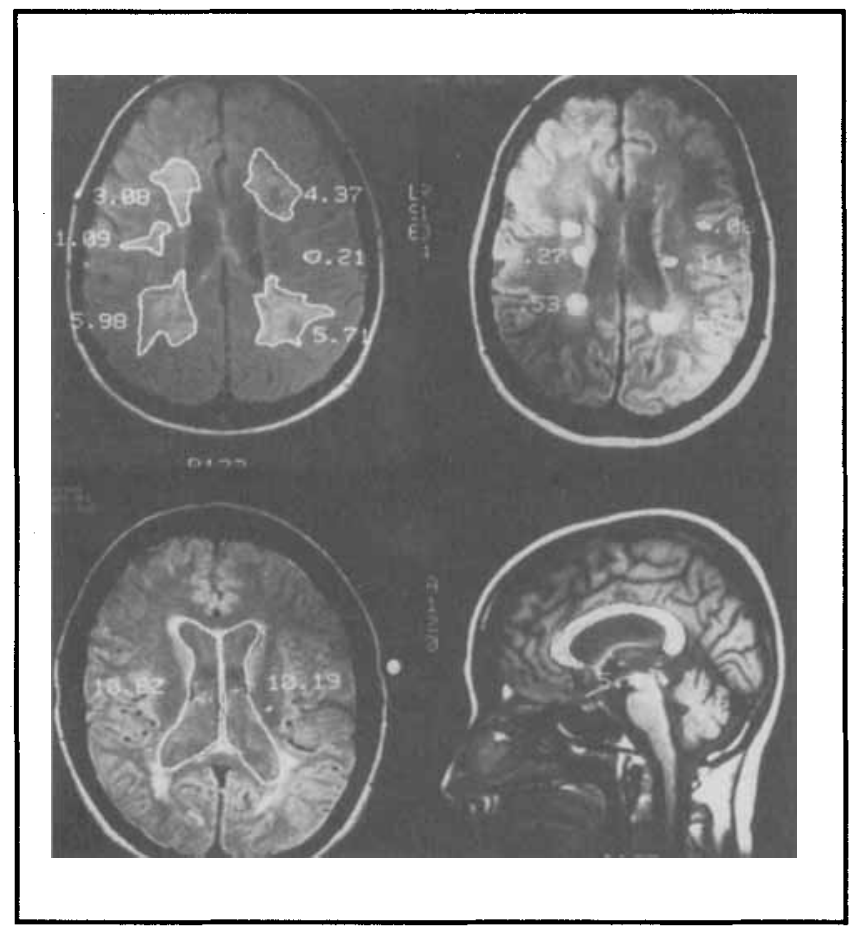

Figure 1. The two top MRIs illustrate the outlining and measurement of lesions (in $\mathrm{cm}^{2}$ ) for two patients. Note that while the number of lesions is the same for both patients (6), major differences exist in the total lesion area (20.4 versus $2.0 \mathrm{~cm}^{2}$ ) and average lesion size (3.4 versus $0.3 \mathrm{~cm}^{2}$ ). The lower left scan demonstrates the outlining and measurement of the lateral ventricular spaces (used to compute ventricular-brain ratios), while the lower right scan shows the measurement of the corpus callosum from the midsagittal scan.

In the present study we administered a comprehensive neuropsychological test battery to a representative sample of MS patients from the community. Size of cerebral lesions and the degree of ventricular and corpus callosum atrophy were quantified from MRIs. Clinicopathologic relationships were evaluated using multivariate statistical procedures which adjust for premorbid differences in cognitive ability.

Methods. Patients. We randomly recruited MS patients from a membership listing of a local MS society. A review of medical records allowed determination of the basis for the diagnosis of MS. We excluded patients not meeting the criteria of Poser et $\mathrm{al}^{13}$ for definite or probable MS and patients with a history of alcohol/drug abuse or nervous system disorder other than MS. Once enrolled, a neurologic examination verified the Poser diagnostic classification and rated patients with regard to disease course, length of symptoms, severity of global dementia (Mini-Mental State Examination ${ }^{14}$ ), and physical disability (Kurtzke Expanded Disability Status Scale [EDSS] ${ }^{15}$ ). Patients subsequently underwent neuropsychological testing and MRI over a 2 -day period to minimize fatigue. Patients gave informed consent according to institutional guidelines.

$M R I$. Imaging was performed on a commercial 1.5 tesla superconductive magnet (General Electric Signa System). We obtained sagittal images with a repetition time (TR) of 600 msec, an echo time (TE) of $20 \mathrm{msec}$, and a 5 -mm slice thickness. These images enabled the selection of a series of axial slices with a TR of 2 seconds and TEs of 25 and 80 msec. The technical factors included two excitations, a $128 \times 256$ matrix, a 5-mm slice thickness, and a 1-mm "skip" between slices.

One investigator, without knowledge of the clinical and neuropsychological profiles of the patients, obtained measurements of total lesion area (TLA), size of the corpus callosum (SCC), and ventricular-brain ratio (VBR). This was accomplished by tracing the outlines of lesions and cerebral structures on the MRI computer console. Software routines available on the GE Signa System computed the area (in $\mathrm{cm}^{2}$ ) subtended by each tracing. We recorded sizes of the following cerebral structures: the third and lateral ventricles from axial slices, the entire area of the brain for each axial slice in which the third or lateral ventricles, or both, could be visualized, and the corpus callosum from the midsagittal slice (see figure 1). We computed TLA by adding all measurements of lesion size for a given patient and VBR by dividing the sum of the ventricular measurements by the sum of the brain area measurements.

Neuropsychological tests. The neuropsychological test battery consisted of measures of verbal intelligence, memory, abstract/conceptual reasoning, attention/concentration, language, and visuospatial skills. We specifically chose tests that do not require fine visual acuity or motor speed/dexterity.

Verbal intelligence was assessed with the six subtests constituting the verbal subscale of the Wechsler Adult Intelligence Scale-Revised (WAIS-R) ${ }^{16}$ : vocabulary, information, digit span (see attention/concentration tests below), comprehension, similarities, and arithmetic.

The recent memory tests consisted of the Buschke Verbal Selective Reminding Test, ${ }^{17}$ the $7 / 24$ Spatial Recall Test, ${ }^{18,19}$ and the Story Recall Test. ${ }^{20}$ The Story Recall Test was administered with immediate, 1-hour, and 24-hour delayed recall. We assessed remote memory by asking the subjects to recall the past eight US presidents (President's Test). ${ }^{20}$ The BrownPeterson Interference Test ${ }^{21,22}$ assesses the rate of forgetting from immediate memory; the stimuli were three 3-letter words, the delay intervals were $0,3,9$, and 18 seconds, and the interference task consisted of counting backwards by 3 during the delay interval. We computed rate of forgetting by subtracting the number of words correctly recalled after an 18-second delay (maximum $=15$ ) from words recalled after no delay (maximum $=15)$.

Tests of abstract/conceptual reasoning skills consisted of the Wisconsin Card Sorting Test, ${ }^{23}$ Booklet Category Test, ${ }^{24}$ Standard Raven Progressive Matrices, ${ }^{25}$ and Stroop Color/ Word Interference Test ${ }^{26}$ (total time to read a color list was subtracted from total time to read the color-word list).

Assessment of attention/concentration skills included forward and backward digit span (WAIS-R instructions), simple versus two-choice complex reaction time $(R T)^{27}$ (simple RT was subtracted from complex RT), Sternberg Memory Scanning Task ${ }^{28}$ (which yields two measures: slope, a measure of mental processing speed; and y-intercept, a measure of overall motor reaction time), and Paced Auditory Serial Addition Test $^{29}$ (using two conditions based on different rates of stimulus presentation: for the "easy" condition, 60 single digits were presented at 3-second intervals, and for the "hard" condition, 60 digits were presented at 2 -second intervals).

The language measures used in this study assessed primarily expressive abilities. These included an abbreviated (15item) version of the Boston Naming Test, ${ }^{20}$ Controlled Oral Word Association Test (F-A-S version), ${ }^{30}$ and Category Word Generation Test (animal names version). ${ }^{20}$

We assessed visuospatial skills with the Hooper Visual Organization Test ${ }^{31}$ and three tests from Benton et $\mathrm{al}^{32}$ : Judgment of Line Orientation, Facial Recognition, and Visual Form Discrimination. 
Table 1. Clinical characteristics of $\mathrm{MS}$ sample $(\mathbf{N}=\mathbf{5 3})$

$\begin{array}{lrl}\text { Sex (males/females) } & 13 / 40 & \\ \text { Age in years (mean) } & 43.9 & \text { (range, 27-61) } \\ \text { Education in years (mean) } & 13.6 & \text { (range, 8-20) } \\ \text { Occupation (6-pt. scale, mean) } & 4.1 & \text { (range, 2-6) } \\ \text { Estimated premorbid IQ* (mean) } & 106.1 & \text { (range, 89-118) } \\ \text { Length of symptoms in years (mean) } & 12.2 & \text { (range, 1-33) } \\ \text { Years since diagnosis (mean) } & 7.8 & \text { (range, 1-28) } \\ \text { Kurtzke Expanded DSS (mean) } & 3.8 & \text { (range, 0-8) } \\ \text { Diagnostic category } & & \\ \quad \text { Clinically definite (no.) } & 37 & (70 \%) \\ \quad \text { Laboratory definite } & 10 & (19 \%) \\ \quad \text { Clinically probable } & 6 & (11 \%) \\ \text { Clinical course } & & \\ \quad \text { Relapsing-remitting (no.) } & 21 & (40 \%) \\ \text { Chronic-progressive } & 10 & (19 \%) \\ \text { Chronic-stable } & 21 & (39 \%) \\ \text { Benign } & 1 & (2 \%) \\ \text { Mini-Mental State (max. }=30 ; \text { mean) } & 28.8 & \text { (range, 12-30) } \\ & & \\ \text { * Estimated from demographic variables using regression formula } \\ \text { derived from WAIS-R standardization sample.40 }\end{array}$

Data analysis. Statistical analyses were performed with the microcomputer version of the Statistical Package for the Social Sciences. ${ }^{33}$ We performed separate stepwise multiple regression analyses for each of the 34 cognitive measures, which served as the dependent (criterion) variables. The independent (predictor) variables were age, education, TLA, VBR, and SCC. Age and education were always entered on the first step to adjust for their effects on the cognitive variables and to adjust for the effects of age on VBR (see below).

We employed cluster analysis (nearest centroid sorting method $^{34}$ ) to classify patients into two subgroups: patients with relatively substantial cognitive impairment ("Impaired") versus those with relatively minimal impairment ("Intact"). Thus, we selected a two-group cluster solution a priori, with the analysis performed on the 10 cognitive test variables shown to be the most sensitive to cognitive dysfunction in MS patients from previous neuropsychological investigations. ${ }^{19,35-39}$ The variables included long-term storageSelective Reminding Test, immediate recall-Story Recall Test, number of perseverative errors-Wisconsin Card Sorting Test, total errors-Booklet Category Test, number correct-Raven Progressive Matrices, time difference between color/word and word reading-Stroop Interference Test, T-score-Hooper Visual Organization Test, scanning rateSternberg Memory Scanning Task, percent correct-hard form of the Paced Auditory Serial Addition Test, and total words generated-Controlled Oral Word Association Test. As in earlier studies, ${ }^{19}$ we performed cluster analysis on the standardized residual scores generated from regression analyses relating cognitive test scores (criterion variable) with demographic (predictor) variables (ie, age, education, sex, and occupation). This method minimizes individual differences in premorbid ability levels.

Results. A total of 59 patients were enrolled in the study. We eliminated six patients from the final analysis: four did not complete MRI due to claustrophobia, one did not meet the criteria of Poser et al $^{13}$ after completion of the neurologic examination, and one had a brainstem arteriovenous malformation diagnosed by MRI. All but two patients were in clinical remission at the time of evaluation. Table 1 presents demographic and illness characteristics for the patient sample.
Table 2. Results of stepwise multiple regression analyses showing MRI variables (in rank order) making significant contributions to the prediction of cognitive test performance after partialling out age and education

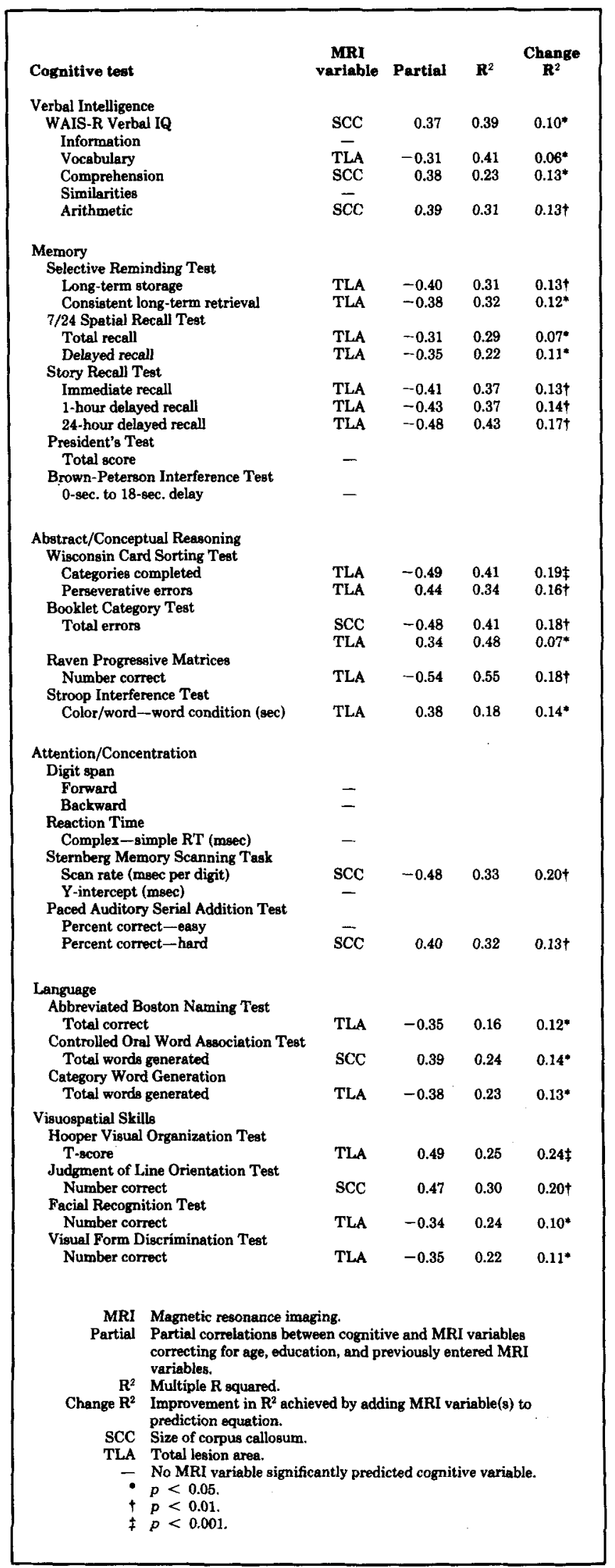


Table 3. Results of cluster analysis

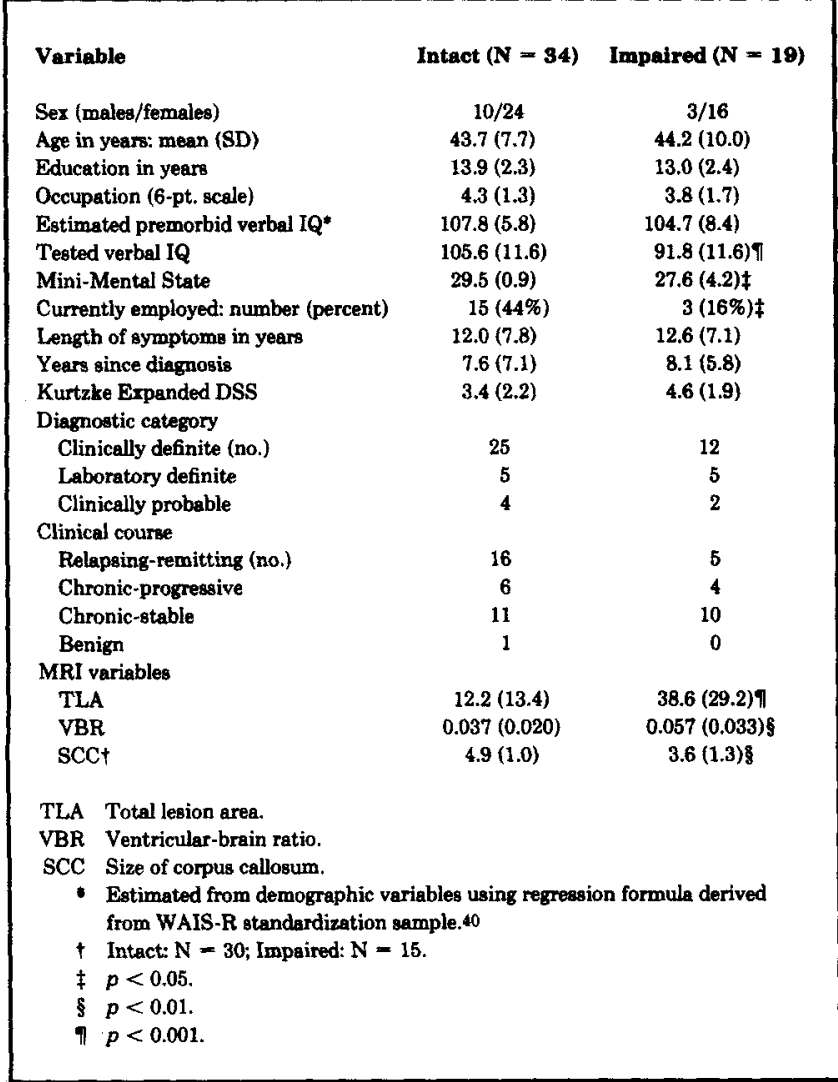

MRI measurements. We obtained TLA and VBR measurements for all 53 patients and SCC measurements for 45 of 53 patients in which precise midline saggital cuts were available. All but one patient had at least a single cerebral lesion. The following summarizes the mean, standard deviation, and range values for the three MRI variables: TLA, 21.7 (in $\mathrm{cm}^{2}$ ), 23.9, 0 to 95 ; VBR, 0.044, 0.027, 0.006 to 0.133; and SCC, 4.49 (in $\left.\mathrm{cm}^{2}\right), 1.28,1.01$ to 7.08 . The three MRI variables correlated significantly with each other: $r=0.61$ for TLA and VBR $(p<0.001), \mathrm{r}=-0.46$ for TLA and SCC $(p<0.01)$, and $\mathrm{r}=-0.48$ for VBR and SCC $(p<$ $0.001)$. Age correlated significantly with $\operatorname{VBR}(r=0.42$, $p<0.01$ ), but not with TLA or SCC.

Stepwise regression analysis. Table 2 presents the results of stepwise multiple regression analyses for each of the cognitive variables. This table includes only those MRI variables making a significant $(p<0.05)$ contribution to the prediction of cognitive test performance. The partial correlation coefficients (labeled "Partial" in table 2) represent the magnitude of the relationship between the cognitive and MRI variables after the effects of age and education are statistically removed. The sign of the coefficient indicates whether the relationship was positive or negative. The partial correlations ranged from -0.31 (vocabulary subtest of the WAIS- $R$ with TLA) to -0.54 (Raven Progressive Matrices and TLA).

The cumulative amount of shared variance between the dependent and independent variables was estimated by the squared multiple correlation coefficient
(" $R$ ") in table 2). Multiplying this value by 100 gives the percent of variance in each cognitive measure accounted for by the MRI variable(s), age, and education. The amount of shared variance ranged from $55 \%$ (a strong relationship) for the Raven Progressive Matrices to $16 \%$ (a weak relationship) for the Abbreviated Boston Naming Test.

The amount of shared variance accounted for by the specific addition of the MRI variable to the regression equation, excluding the effects of age and education, was estimated by the change in the squared multiple correlation coefficient ("Change $\mathrm{R}^{2 \text { " }}$ in table 2). These values ranged from $24 \%(p<0.001)$ for the Hooper Visual Organization Test to $6 \%(p<0.05)$ for the vocabulary subtest.

At least one MRI variable significantly $(p<0.05)$ predicted 25 of $34(74 \%)$ cognitive test variables. Of these 25 cognitive variables, TLA predicted 18 and SCC predicted eight; two MRI variables, SCC and TLA, predicted performance on the Booklet Category Test, an abstract/conceptual reasoning test. VBR did not independently predict any of the cognitive variables.

TLA was the best predictor of performance on measures of recent memory and abstract/conceptual reasoning while SCC was the best predictor of information processing speed (scan rate on the Sternberg test), sustained attention and rapid problem solving (hard form of the Paced Auditory Serial Addition Test), and mental arithmetic (arithmetic subtest of the WAIS-R). Various tests of verbal intelligence, linguistic processes, and visuospatial problem solving skills were predicted by both TLA and SCC (see table 2).

Cluster analysis. Table 3 presents the results of the two-group cluster solution. Nineteen patients (36\%) performed below expectations on neuropsychological testing ("Impaired" group; mean cluster center = -0.691 ), while 34 patients $(64 \%)$ performed at or slightly above expectations ("Intact" group; mean cluster center $=+0.358$ ). No significant group differences were observed on demographic variables and on estimated premorbid verbal IQ derived from demographic variables. ${ }^{40}$

In contrast, we observed a significant group difference on current WAIS-R verbal IQ $(t=4.13, \mathrm{df}=51$, $p<0.0001$ ). There was also a small but statistically significant difference between the clusters on the MiniMental State $(t=2.55, \mathrm{df}=51, p<0.02)$; mean values for both groups were in the nondemented range, however. ${ }^{14}$ While the two groups did not differ in duration of symptoms, disease course, or overall physical disability (Kurtzke EDSS), it is noteworthy that patients in the cognitively impaired group were less likely to be employed than patients in the cognitively intact group (16\% versus $44 \%$, respectively; chi-square $=4.36, \mathrm{df}=$ $1, p<0.04)$.

Also listed in table 3 are the means and standard deviations of the three MRI variables for the two clusters. The impaired group had significantly greater TLA $(p<0.001)$ and VBR $(p<0.01)$, and smaller SCC $(p<$ 0.01 ), than the intact group. Figure 2 presents MRI values for individual subjects in each cluster. Of the three MRI variables, the TLA variable achieved the 

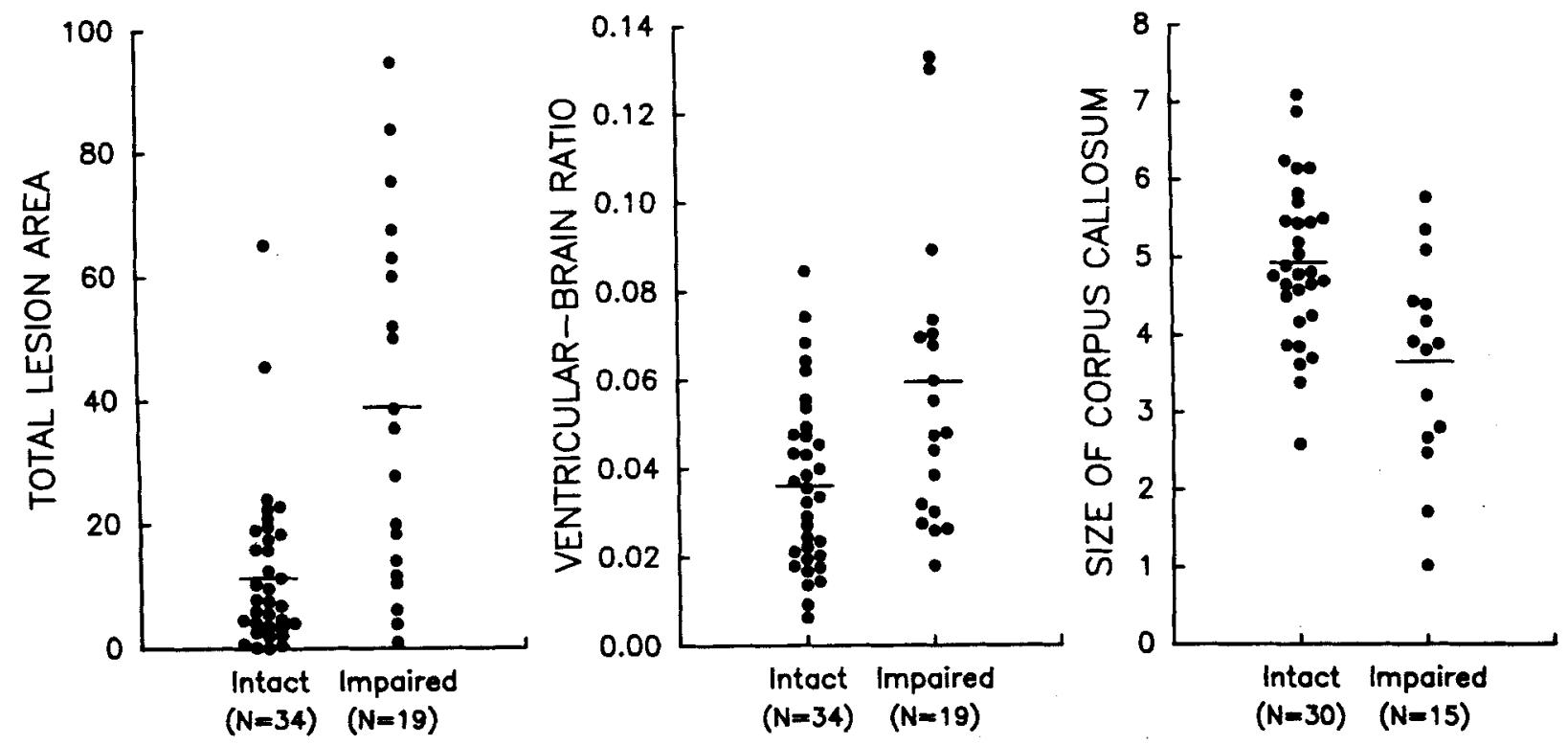

$-=$ Mean

Figure 2. Total lesion area, ventricular-brain ratio, and size of the corpus callosum for cognitively intact and impaired MS patients.

greatest degree of cluster separation. Ten of $12(83 \%)$ patients with TLA greater than $30 \mathrm{~cm}^{2}$ were members of the cognitively impaired cluster; conversely, 32 of 41 (78\%) patients with TLA less than $30 \mathrm{~cm}^{2}$ were in the cognitively intact group.

Discussion. The results of this study demonstrate a strong relationship between the severity of cerebral pathology on MRI and cognitive dysfunction in MS patients. The robust MRI correlations in the present study contrast with the weak or nonexistent correlations obtained in previous studies that have relied on the neurologic examination as the indicator of cerebral involvement. ${ }^{3-6}$ This may be explained by the neurologic examination underestimating cognitive dysfunction in MS patients when compared with results derived from neuropsychological testing. ${ }^{38}$

We observed the strongest clinicopathologic correlations on measures of recent memory and abstract/ conceptual reasoning, skills that are most often impaired in MS patients. ${ }^{7,11}$ We also observed significant correlations between MRI variables and skills infrequently studied in MS patients: rapid and sustained problem solving, language, and visuospatial skills. These findings suggest that cerebral demyelination may be associated with a wider range of cognitive dysfunction than previously suspected.

The relationship between the degree of corpus callosum atrophy and performance on tasks requiring sustained attention and rapid problem solving raises the possibility that such performance depends on precisely timed interhemispheric communication that is disrupted by demyelinated callosal fiber tracts. This obser- vation also suggests that specific cognitive processes may be disrupted by demyelinating lesions involving relatively focal morphologic structures.

Ventricular size did not independently predict cognitive performance beyond what could be predicted by measures of lesion area and callosal atrophy. In a previous study, ${ }^{41}$ we demonstrated statistically significant, albeit weak, correlations between ventricular enlargement and cognitive performance in MS patients. Ventricular enlargement presumably results from "thinning" of the periventricular white matter as a consequence of demyelination. As such, ventricular enlargement is an indirect, and presumably late, marker of disease activity within the cerebrum.

Results of the cluster analysis suggest that if the total lesion load on MRI is excessive (arbitrarily defined as greater than $30 \mathrm{~cm}^{2}$ in the present study), there is a high probability that an MS patient will have cognitive impairment. The practical significance of identifying $\operatorname{cog}$ nitive dysfunction is highlighted by the observation that MS patients with cognitive impairment are less likely to be employed than patients without cognitive impairment. We observed this relationship despite the fact that the two clusters did not differ in severity of physical disability, duration of illness, or disease course.

We found no relationship between duration of illness and degree of MRI abnormalities; furthermore, this study, as well as others, $19,42,43$ found no relationship between duration of illness and severity of cognitive disturbance. These negative findings may result from limitations of the cross-sectional research design used in this and other studies. Longitudinal studies are therefore needed to examine the natural history of cog- 
nitive dysfunction in MS, particularly in light of disease progression as visualized by MRI.

\section{Acknowledgment}

The assistance of the Multiple Sclerosis Society of Milwaukee is gratefully appreciated.

\section{References}

1. Lukes SA, Crooks LE, Aminoff MJ, et al. Nuclear magnetic resonance imaging in multiple sclerosis. Ann Neurol 1983;13:592-601.

2. Young IR, Hall AS, Pallis CA, Legg NJ, Bydder GM, Steiner RE. Nuclear magnetic resonance imaging of the brain in multiple sclerosis. Lancet 1981;2:1063-1066.

3. Jacobs L, Kinkel WR, Polachini I, Kinkel RP. Correlations of nuclear magnetic resonance imaging, computerized tomography, and clinical profiles in multiple sclerosis. Neurology 1986;36:27-34.

4. Kirshner HS, Tsai SI, Runge VM, Price AC. Magnetic resonance imaging and other techniques in the diagnosis of multiple sclerosis. Arch Neurol 1985;42:859-863.

5. Reese L, Carr TJ, Nicholson RL, Lepp EK. Magnetic resonance imaging for detecting lesions of multiple sclerosis: comparison with computed tomography and clinical assessment. Can Med Assoc J 1986;135:639-643.

6. Edwards MK, Farlow MR, Stevens JC. Multiple sclerosis: MRI and clinical correlation. AJNR 1986;7:595-598.

7. Rao SM. Neuropsychology of multiple sclerosis: a critical review. J Clin Exp Neuropsychol 1986;8:503-542.

8. Van den Burg W, van Zomeren AH, Minderhoud JM, Prange AJA, Meijer NSA. Cognitive impairment in patients with multiple sclerosis and mild physical disability. Arch Neurol 1987;44:494-501.

9. Franklin GM, Heaton RK, Nelson LM, Filley CM, Seibert C. Correlation of neuropsychological and MRI findings in chronic/ progressive multiple sclerosis. Neurology 1988;38:1826-1829.

10. Huber SJ, Paulson GW, Shuttleworth EC, et al. Magnetic resonance imaging correlates of dementia in multiple sclerosis. Arch Neurol 1987;44:732-736.

11. Peyser JM, Poser CM. Neuropsychological correlates of multiple sclerosis. In: Filskov SB, Boll TJ, eds. Handbook of clinical neuropsychology, vol 2. New York: John Wiley \& Sons, 1986:364-397.

12. Prigatano GP, Parsons OA. Relationship of age and education to Halstead Test performance in different patient populations. $J$ Consult Clin Psychol 1976;44:527-533.

13. Poser CM, Paty DW, Scheinberg L, et al. New diagnostic criteria for multiple sclerosis: guidelines for research protocols. Ann Neurol 1983;13:227-231.

14. Folstein MF, Folstein SE, McHugh PR. Mini-Mental State: a practical method for grading the cognitive state of patients for the clinician. J Psychiatr Res 1975;12:189-198.

15. Kurtzke JF. Rating neurologic impairment in multiple sclerosis: an expanded disability status scale (EDSS). Neurology 1983;33:1444-1452.

16. Wechsler D. Manual for the Wechsler Adult Intelligence ScaleRevised. New York: Psychological Corporation, 1981.

17. Buschke H, Fuld PA. Evaluating storage, retention, and retrieval in disordered memory and learning. Neurology 1974;24:1019-1025.
18. Barbizet J, Cany E. Clinical and psychometrical study of a patient with memory disturbances. Int J Neurol 1968;7:44-54.

19. Rao SM, Hammeke TA, McQuillen MP, Khatri BO, Lloyd D. Memory disturbance in chronic progressive multiple sclerosis. Arch Neurol 1984;41:625-631.

20. Caine ED, Bamford KA, Schiffer RB, Shoulson I, Levy S. A controlled neuropsychological comparison of Huntington's disease and multiple sclerosis. Arch Neurol 1986;43:249-254.

21. Brown J. Some tests of the decay theory of immediate memory. Q J Exp Psychol 1958;10:12-21.

22. Peterson LR, Peterson MJ. Short-term retention of individual verbal items. J Exp Psychol 1959;58:193-198.

23. Heaton RK. Wisconsin Card Sorting Test manual. Odessa, FL: Psychological Assessment Resources, 1981.

24. DeFilippis NA, McCampbell E. The Booklet Category Test manual. Odessa, FL: Psychological Assessment Resources, 1979.

25. Raven JC. Guide to the Standard Progressive Matrices. London: HK Lewis, 1960.

26. Stroop JR. Studies of interference in serial verbal reactions. J Exp Psychol 1935;18:643-662.

27. Benton AL. Interactive effects of age and brain disease on reaction time. Arch Neurol 1977;34:369-370.

28. Sternberg S. Memory scanning: mental processes revealed by reaction-time experiments. Am Scientist 1969;57:421-457.

29. Gronwall DMA. Paced auditory serial-addition task: a measure of recovery from concussion. Percept Mot Skills 1977;44:367-373.

30. Benton AL, Hamsher KdeS. Multilingual Aphasia Examination. Iowa City, IA: University of Iowa Press, 1976.

31. Hooper HE. The Hooper Visual Organization Test manual. Los Angeles: Western Psychological Services, 1958.

32. Benton AL, Hamsher KdeS, Varney NR, Spreen O. Contributions to neuropsychological assessment: a clinical manual. New York: Oxford University Press, 1983.

33. Norusis MJ. SPSS/PC + for the IBM PC/XT/AT. Chicago: SPSS, 1986.

34. Anderberg MR. Cluster analysis for applications. New York: Academic Press, 1973

35. Rao SM, Hammeke TA, Speech TJ. Wisconsin Card Sorting Test performance in relapsing-remitting and chronic-progressive multiple sclerosis. J Consult Clin Psychol 1987;55:263-265.

36. Rao SM, Leo GJ, St Aubin-Faubert P. On the nature of memory disturbance in multiple sclerosis. J Clin Exp Neuropsychol (in press).

37. Rao SM, St Aubin-Faubert P, Leo GJ. Information processing speed in patients with multiple sclerosis. J Clin Exp Neuropsychol (in press).

38. Peyser JM, Edwards KR, Poser CM, Filskov SB. Cognitive function in patients with multiple sclerosis. Arch Neurol 1980;37:577-579.

39. Lincoln NB. Discrepencies between capabilities and performance of activities of daily living in multiple sclerosis patients. Int Rehabil Med 1981;3:84-88.

40. Barona A, Reynolds CR, Chastain R. A demographically based index of premorbid intelligence for the WAIS-R. J Consult Clin Psychol 1984;52:885-887.

41. Rao SM, Glatt S, Hammeke TA, et al. Chronic progressive multiple sclerosis: relationship between cerebral ventricular size and neuropsychological impairment. Arch Neurol 1985;42:678-682.

42. Marsh G. Disability and intellectual function in multiple sclerosis. J Nerv Ment Dis 1980;168:758-762.

43. Ivnik RJ. Neuropsychological test performance as a function of MS-related symptomatology. J Clin Psychiatry 1978;39:304-307. 


\section{Neurology}

\section{Correlation of magnetic resonance imaging with neuropsychological testing in multiple sclerosis}

S. M. Rao, G. J. Leo, V. M. Haughton, et al.

Neurology 1989;39;161

DOI 10.1212/WNL.39.2.161

\section{This information is current as of February 1, 1989}

Updated Information \&

Services

Citations

Permissions \& Licensing

Reprints including high resolution figures, can be found at: http://n.neurology.org/content/39/2/161.full

This article has been cited by 27 HighWire-hosted articles: http://n.neurology.org/content/39/2/161.full\#\#otherarticles

Information about reproducing this article in parts (figures,tables) or in its entirety can be found online at:

http://www.neurology.org/about/about_the_journal\#permissions

Information about ordering reprints can be found online:

http://n.neurology.org/subscribers/advertise

Neurology ${ }^{\circledR}$ is the official journal of the American Academy of Neurology. Published continuously since 1951, it is now a weekly with 48 issues per year. Copyright (C) 1989 by AAN Enterprises, Inc.. All rights reserved. Print ISSN: 0028-3878. Online ISSN: 1526-632X.

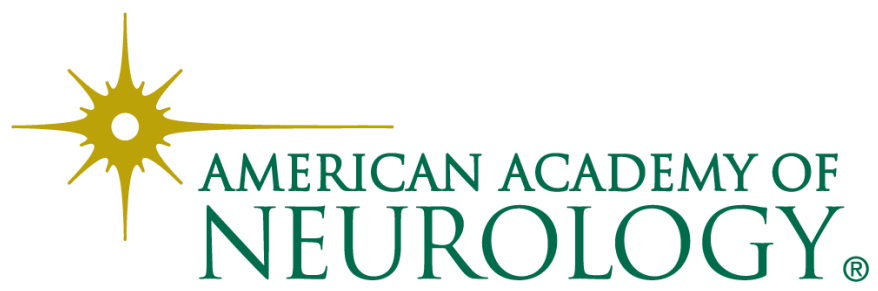

